Volume 9, No.4, July - August 2020

International Journal of Advanced Trends in Computer Science and Engineering

Available Online at http://www.warse.org/IJATCSE/static/pdf/file/ijatcse294942020.pdf

https://doi.org/10.30534/ijatcse/2020/294942020

\title{
Prospects for Creating Sub-Millimeter Magnetrons
}

\author{
Mykhailo Kopot ${ }^{1}$, M. Ayaz Ahmad ${ }^{2}$, Vyacheslav Lyashenko ${ }^{3}$, Syed Khalid Mustafa ${ }^{4}$ \\ ${ }^{1}$ Department of Software Engineering, Kharkiv National University of Radioelectronics, Ukraine, \\ mykhaylo.kopot@nure.ua \\ ${ }^{2}$ Department of Physics, Faculty of Science, University of Tabuk, Saudi Arabia, mayaz.alig@ gmail.com \\ ${ }^{3}$ Department of Informatics, Kharkiv National University of RadioElectronics, Ukraine, \\ lyashenko.vyacheslav@gmail.com \\ ${ }^{4}$ Department of Chemistry, Faculty of Science, University of Tabuk, Saudi Arabia, \\ khalid.mustafa938@gmail.com
}

\begin{abstract}
The development of new technology requires an integrated approach to solving various issues that may arise. One of the directions of development of new devices is the change in its design features. This fully applies to the prospects for creating sub-millimeter magnetrons. The paper considers the design features of classical magnetrons. Ways of improving magnetrons are proposed. In particular, it is proposed to consider a reversed magnetron. We note the design features of such magnetrons. For this, we highlight the different locations of the auto cathode. We also highlighted the characteristics of magnetrons that are discussed in this paper.
\end{abstract}

Key words: Reversed Magnetron, Secondary Emission, Field Emission, Field Emission Cathode

\section{INTRODUCTION}

The development of any type of device is to improve its operational parameters. In this row there are also M-type generators. The M-type generator is a magnetron. The magnetron generates microwave radiation, in which the interaction of electrons with the electric component of the microwave field occurs in a space where the constant magnetic field is perpendicular to the constant electric field [1]-[3]. Magnetrons are used in radar technology, in microwave ovens. Magnetrons can operate at various frequencies and powers.

The main parameters of magnetron operation are the generated power, the generation frequency, and the duration of its continuous operation. For various purposes, magnetrons of a certain design are used. But it is the design of magnetrons that can be decisive for achieving the basic parameters of such a device. Therefore, the question of choosing a magnetron design is still open and controversial for obtaining certain characteristics. In particular, it is important to achieve a higher generation frequency and increase duration of its continuous operation. These issues are the main focus of the work.

\section{CLASSICAL MAGNETRON AS THE BASIS FOR THE DEVELOPMENT OF OTHER SUBSPECIES OF MAGNETRONS}

The classic magnetron consists of an anode block, a cathode, magnets and a wire loop (a kind of energy output). The resonators of the magnetron form an annular oscillatory system; in the interaction space, the interaction of the electron beam and the electromagnetic wave occurs. Magnetrons can have different types of resonators: scapular, slotted or slot-hole.

At the same time, a device in which the cathode (thermionic) is located inside the anode slowing retarding system (AZS) in which resonators are cut in some way can be considered a classical magnetron. As a rule, the magnetron operates on $\pi$ -type vibrations.

An example of such a magnetron is shown in Figure 1 [4]-[6].
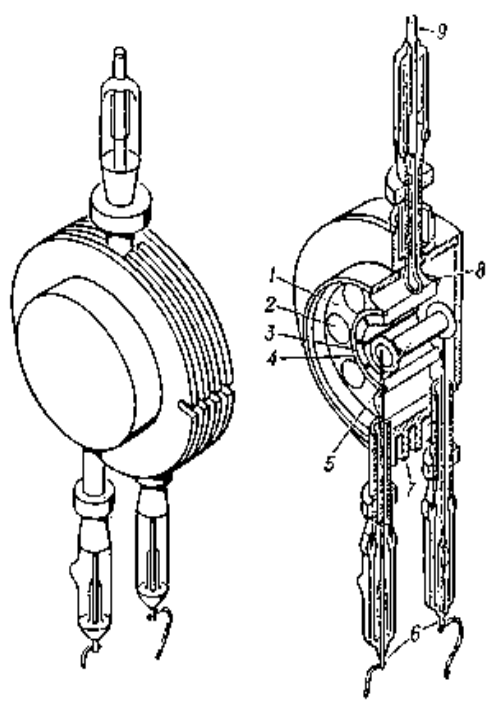

Figure 1: Classic slot-hole magnetron (left - external view; right section) 
Figure 1 shows: 1 - anode block with 8 slot-hole resonators; 2 - resonator; 3 - lamella of the anode block; 4 - a bunch in the form of a metal ring (the second same ring is located on the other end of the anode block); 5 - cathode; 6 - leads of the cathode heater; 7 - radiator; 8 - communication loop for outputting microwave energy; 9 - microwave energy output rod for connection to a coaxial line.

Also, the magnetron can operate on non- $\pi$ vibrations. This mode of operation of the magnetron lies in the fact that it can be implemented using a spatial harmonic. The creation of magnetrons in the short-wavelength part of the millimeter wavelength range, as a rule, is based on the synchronism of the electron flux with the lowest spatial harmonic of the degenerate mode of oscillations of an equal resonator system.

Due to a more effective deceleration factor with the same number of resonators, in comparison with a $\pi$-shaped system, it is possible to achieve wider dimensions of the interaction space. This allows you to get the greatest durability, as well as to simplify the manufacture of the cathode. As a rule, species met these conditions $\pi / 2+/-1$. This expanded the possibilities for the development and use of magnetrons. This harmonic could be achieved at lower operating voltages compared to the $\pi$-type in this design, with a satisfactory separation of vibration types (meaning adjacent species).

Nevertheless, the further development and use of classical types of magnetrons is limited by such parameters as the generation frequency and the duration of continuous operation. This makes it necessary to consider and create new types of magnetron. Among these types of magnetron, the appearance of a reversed magnetron should be distinguished. We should also highlight the magnetron with a cold main cathode for field emission triggering. The main mode of operation of such magnetrons is their operation at the spatial harmonic.

\section{REVERSE VIEW OF THE MAGNETRON AS A POSSIBLE VARIANT OF THE DEVELOPMENT OF M-TYPE GENERATORS OF THE MILLIMETER WAVELENGTH RANGE}

A reversed magnetron is a device in which the anode and cathode systems are reversed. Then the resonators are cut at the inner electrode, and the cathode covers the entire slowing retarding system. Moving to the higher frequency region, the resonators become smaller.

At the same time, quite a lot of resonators can be placed over a large length of the anode. But a resonator system with a large number of resonators has a small separation of vibration types. This is unacceptable for reliable start-up and operation of the device. Therefore, it is necessary to reduce the diameter of the anode system. But a decrease in the anode diameter leads to a decrease in the cathode diameter. A decrease in the cathode diameter leads to a decrease in the emission area. In addition, as the diameter of the thermionic cathode decreases, it rapidly burns out. Thus, the duration of continuous work is rapidly decreasing.

Inversion of the anode with the cathode - in a certain way solves this problem. This is based on the fact that in this case the emission area increases markedly.

Suppose we have a hypothetical device with a classical millimeter wave design with the following dimensions:

cathode radius $1.2 \mathrm{~mm}$,

anode radius $2.4 \mathrm{~mm}$.

Take a reversed device with the same number of resonators and the same anode radius. In other words, the base of the lamellas is closer to the center of the appliance. In this case, the radius of the cathode will be approximately $3.6 \mathrm{~mm}$. Obviously, the cathode radius has increased from $1.2 \mathrm{~mm}$ to $3.6 \mathrm{~mm}$. This will lead to an increase in the azimuthal cathode length from $7.53 \mathrm{~mm}$ to $22.6 \mathrm{~mm}$, which increases the cathode emission area by a factor of 3 . And accordingly, the MTBF (duration of uninterrupted work) of the device as a whole will be increased.

In this case, the placement of resonators on the inner electrode has its own design features. This is due to the fact that the circumference of the base of the lamella is less than the circumference of their end. To eliminate this, an elliptical resonator can be used. This approach allows you to have a thickening at the base of the lamella and to equalize the ratio of the thickness of the lamella to the gap between them at the level of the interaction space.

When developing sub-millimeter magnetrons, the mode of operation at the spatial harmonic can be selected [7]. A split resonator slowing down system can also be used. A split resonator system is a system consisting of two alternating resonators with different geometric dimensions. The work of such a system is based, as a rule, on $\pi$-type vibrations.

The dispersion characteristic of the split resonator slowing down system is shown in Figure 2.

In Figure 2, on the ordinate axis are the values of the magnetron radiation frequency, on the abscissa axis - the number of the vibration type.

Two curves in Figure 2 correspond to resonators with different geometric dimensions (black curve - for resonators of one geometric size, red curve - for resonators of a different geometric size). 


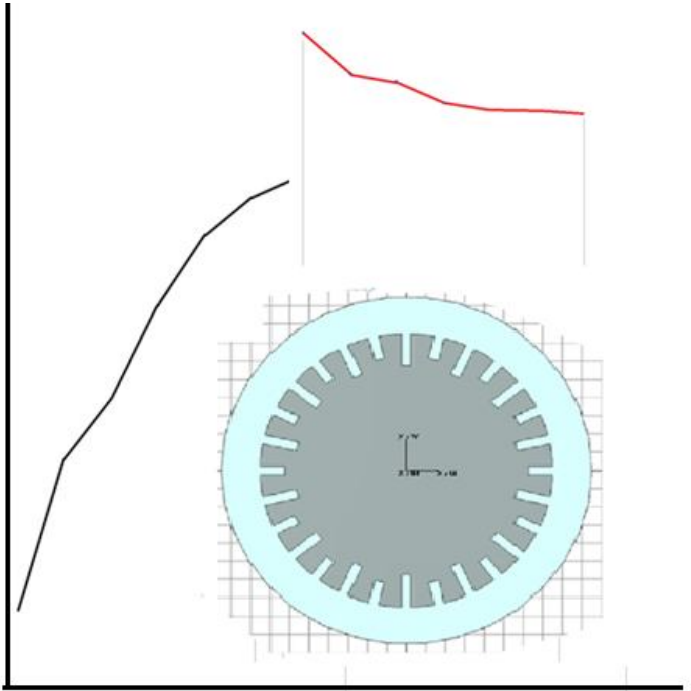

Figure 2: Qualitative assessment of the dispersion characteristics of a split resonators moderating system

Based on the above, we can conclude that the shortest-wave type of generation corresponds to the $\pi / 2$-type. At the same time, in an equally resonator system, the shortest-waveform corresponds to the $\pi$-type. Thus, when operating on a spatial harmonic, a multi-resonator system will generate radiation at the highest-frequency form, as compared to an equally-resonator system.

\section{MTBF AS A TIME CHARACTERISTIC OF THE MAGNETRON PERFORMANCE}

It is known that the magnetron "breaks down" due to the burnout of the thermal cathode [8]. In order to increase the performance of the magnetron, you can use cold, secondary-emission cathodes [9], [10]. However, for the cold cathode to work, in order to induce the process of secondary emission multiplication, it is necessary to have a source of "primary" electrons. As a rule, the same thermo-cathode is used for these purposes. To "start" the main cathode does not require a large current, so the auxiliary cathodes can work in a "sparing" mode. However, this does not fundamentally solve the problem. One of the solutions is the use of auto-emission [11].

But the use of auto-emission for magnetrons is a complex technical problem. Therefore, various systems with a large number of electrodes were built. Then, if in a classical magnetron there are only two electrodes (anode and cathode), then in a magnetron with a cold main cathode there are already three electrodes. An additional or auxiliary cathode played the role of the third one. In the case of field emission triggering of the main cold cathode, the system can have three to four electrodes, depending on the implementation of the auto-cathode.

Figure 3 shows some designs of such systems [12], [13].

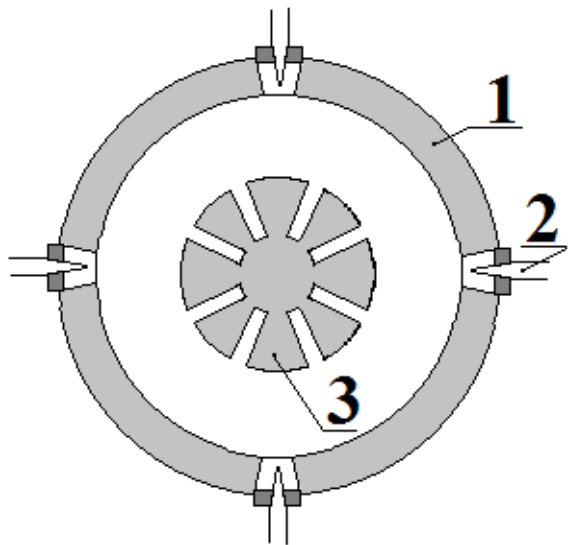

a) auto-cathode system is located perpendicular to the axis of the device

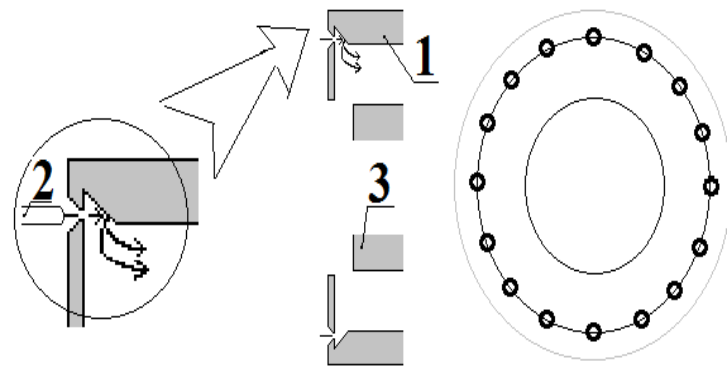

b) auto-cathode system is parallel to the axis of the device

Figure 3: Some design features of the auxiliary cathode for the cold main cathode magnetron

Figure 3 shows:

1 - main cathode,

2 - needle of the field emission cathode,

3 - anode retardation system.

Thus, the use of magnetrons nonincandescent allows you to create new equipment with high performance. These characteristics include:

- the possibility of instantaneous short-term shutdown and switching of operating modes of the equipment, including multiple changes in the duty cycle by a factor of 100 or more;

- increased durability and reliability even at increased loads on the cathode. This is achieved through the use of a "cold" cathode;

- increased reliability due to the elimination of failures of the magnetron filament circuit, relay filament transformer and switches;

- reduced weight of equipment due to the elimination of switches and a lighter power supply; 
- reduced cost of manufacturing equipment by reducing its energy consumption and simplifying its operation and design.

\section{CONCLUSION}

We have examined the design of a classical magnetron. Showed the advantages of such magnetrons and identified their main disadvantages. We have also identified a key direction in the development of magnetrons. This development is associated with an increase in the generation frequency and an increase in the operating time of the device. This is especially important when creating sub-millimeter magnetrons. A reversed magnetron can be used to solve this problem. The paper also notes the design features of such magnetrons. The characteristics of magnetrons, which are considered in the work, are considered separately.

\section{ACKNOWLEDGEMENTS}

The author (Mohammad Ayaz Ahmad) would like to acknowledge the keen support in financial assistance for this work of the Vice Presidency / Studies and Scientific Research/Deanship of Scientific Research on behalf of University of Tabuk, Kingdom of Saudi Arabia and Ministry of Higher Education, K.S.A under the research grant no. S-0263-1436/dated 15-03-1436 [14]-[25]. And also highly acknowledge the Department of Informatics, Kharkiv National University of RadioElectronics, Ukraine in numerous help and support to complete this article.

\section{REFERENCES}

1. P. J. Kelly, and R. D. Arnell. Magnetron sputtering: a review of recent developments and applications, Vacuum, Vol. 56, no. (3, pp. 159-172, 2000. https://doi.org/10.1016/S0042-207X(99)00189-X

2. S. Lienkov, and et al.. The Development of an Intelligent Complex of Radiation-Technological Control of a Safety Barrier, International Journal of Emerging Trends in Engineering Research, Vol. 8, no. 7, pp. 3483-3486, 2020.

https://doi.org/10.30534/ijeter/2020/97872020

3. M. Iasechko, and et al.. Conditions For Reliable Transmission Of Information Over Long Distances Using a Powerful Electromagnetic Radiation, International Journal of Emerging Trends in Engineering Research, Vol. 8, no. 1, pp. 138-144, 2020. https://doi.org/10.30534/ijeter/2020/18812020

4. G. Bräuer, B. Szyszka, M. Vergöhl, and R. Bandorf. Magnetron sputtering-Milestones of 30 years, Vacuum, Vol. 84, no. 12, pp. 1354-1359, 2010. https://doi.org/10.1016/j.vacuum.2009.12.014

5. J. Goerth. Early magnetron development especially in Germany, In 2010 International Conference on the Origins and Evolution of the Cavity Magnetron, pp. 17-22) 2010.

https://doi.org/10.1109/CAVMAG.2010.5565571.
6. A. Y. Nee (Ed.). Handbook of manufacturing engineering and technology, Springer Reference, 2015.

7. I. D. Truten'. Impul'snyye millimetrovyye magnetrony, Sbornik «Elektronika $i$ radiofizika millimetrovykh $i$ submillimetrovykh radiovoln», 1986.

8. C. H. Stoessel, J. C. Withers, C. Pan, D. Wallace, and R. O. Loutfy. Improved hollow cathode magnetron deposition for producing high thermal conductivity graphite-copper composite, Surface and Coatings Technology, Vol. 76, pp. 640-644, 1995.

https://doi.org/10.1016/0257-8972(95)02674-6

9. D. M. Goebel. Cold-cathode, pulsed-power plasma discharge switch, Review of scientific instruments, Vol. 67, no. 9, pp. 3136-3148, 1996. https://doi.org/10.1063/1.1147492

10. V. A. Bespalov, and et al.. Development and Investigation of a Field Emission Medium for Autocathodes of Mobile Power Microwave Devices, Technical Physics, Vol. 63, no. 3, pp. 443-451, 2018. https://doi.org/10.1134/S1063784218030027

11. M. F. Kopylov, and et al.. Avtorskoye svidetel'stvo N 1780444. Prioritet v SSSR ot 23.10.77 g., Opublikovano $v$ ofitsial'nom byulletene komiteta no patentam tovarnym znakam «Izobreteniya», Vol. 8, pp. 216, 1994.

12. V. V. Semenets', M. Kopot', and et al.. Patent Ukrainy №130571, Zayavlen 02.07.2018, opublikovan 10.12.2018, byul. 23, 2019.

13. V. V. Semenets', M. Kopot', and et al.. Patent Ukrainy №133970, Zayavlen 03.12.2018, opublikovan 25.04.2019, byul. 8, 2019.

14. M. Ayaz, I. Tvoroshenko, J. H. Baker, and V. Lyashenko. Modeling the Structure of Intellectual Means of Decision-Making Using a System-Oriented NFO Approach, International Journal of Emerging Trends in Engineering Research, Vol. 7, no. 11, pp. 460-465, 2019. https://doi.org/10.30534/ijeter/2019/107112019

15. Vyacheslav Lyashenko, Syed Khalid Mustafa, Svitlana Sotnik, M. Ayaz Ahmad. Basic Principles of Decision Making upon Receipt of New Nanomaterial, International Journal of Advanced Trends in Computer Science and Engineering (IJATCSE), Vol. 8, no. 5, (2019), pp. 2680-2685.

https://doi.org/10.30534/ijatcse/2019/124852019

16. Vyacheslav Lyashenko, Syed Khalid Mustafa, Nataliya Belova, M. Ayaz Ahmad. Some Features in Calculation of Mold Details for Plastic Products, International Journal of Emerging Trends in Engineering Research (IJETER), Vol. 7, no. 11, (2019), pp. 720-724. https://doi.org/10.30534/ijeter/2019/517112019

17. Vyacheslav Lyashenko, Syed Khalid Mustafa, Irina Tvoroshenko, M. Ayaz Ahmad. Methods of Using Fuzzy Interval Logic During Processing of Space States of Complex Biophysical Objects, International Journal of Emerging Trends in Engineering Research (IJETER), Vol. 8, no. 2, (2020), pp. 372-377. https://doi.org/10.30534/ijeter/2020/22822020

18. M. Ayaz Ahmad, Syed Khalid Mustafa, Oleksandr Zeleniy, Vyacheslav Lyashenko. Wavelet Coherence as a Tool for Markers Selection in the Diagnosis of Kidney Disease, International Journal of Emerging 
Trends in Engineering Research (IJETER), Vol. 8, no. 2, (2020), pp. 378-383.

https://doi.org/10.30534/ijeter/2020/23822020

19. Irina Tvoroshenko, M. Ayaz Ahmad, Syed Khalid Mustafa, Vyacheslav Lyashenko, Adel R. Alharbi. Modification of Models Intensive Development Ontologies by Fuzzy Logic, International Journal of Emerging Trends in Engineering Research (IJETER), Vol. 8, no. 3 (2020), pp. 939-944. https://doi.org/10.30534/ijeter/2020/50832020

20. Svitlana Sotnik, Syed Khalid Mustafa, M. Ayaz Ahmad, Vyacheslav Lyashenko, Oleksandr Zeleniy. Some Features of Route Planning as the Basis in a Mobile Robot, International Journal of Emerging Trends in Engineering Research (IJETER), Vol. 8, no. 5 (2020), pp. 2074-2079. https://doi.org/10.30534/ijeter/2020/97852020

21. M. Ayaz, T. Sinelnikova, S. K. Mustafa, and V. Lyashenko. Features of the Construction and Control of the Navigation System of a Mobile Robot, International Journal of Emerging Trends in Engineering Research, Vol. 8, no. 4, pp. 1445-1449, 2020. https://doi.org/10.30534/ijeter/2020/82842020

22. M. Ayaz, I. Tvoroshenko, J. H. Baker, and V. Lyashenko. Computational Complexity of the Accessory Function Setting Mechanism in Fuzzy Intellectual Systems, International Journal of Advanced Trends in Computer Science and Engineering, Vol. 8, no. 5, pp. 2370-2377, 2019. https://doi.org/10.30534/ijatcse/2019/ 77852019

23. Muncho J. Mbunwe, M. Ayaz Ahmad, Syed Khalid Mustafa, An effective energy saving design strategy to maximize the use of electricity, J. Math. Comput. Sci., Vol. 10(5), (2020), pp. 1808-1833. https://doi.org/10.28919/jmcs/4775

24. Syed Khalid Mustafa, Mykhailo Kopot, M. Ayaz Ahmad, Valentin Lyubchenko, Vyacheslav Lyashenko, Interesting Applications of Mobile Robotic Motion by using Control Algorithms, International Journal of Advanced Trends in Computer Science and Engineering (IJATCSE), Vol. 9(3), (2020), pp. 3847-3852. https://doi.org/10.30534/ijatcse/2020/203932020

25. M. A. Ahmad, S. K. Mustafa, O. Zeleniy O., and V. Lyashenko. Wavelet Coherence as a Tool for Markers Selection in the Diagnosis of Kidney Disease, International Journal of Emerging Trends in Engineering Research, Vol. 8, no. 2, pp. 378-383, 2020. https://doi.org/10.30534/ijeter/2020/23822020 